\title{
PEMANTAUAN PENGENDALIAN VEKTOR PADA SANTRI SEBAGAI UPAYA PENGGERAK PERILAKU HIDUP BERSIH DAN SEHAT DI PONPES SABILUNNAJAT
}

\section{MONITORING OF VECTOR CONTROL BY SANTRI AS AN EFFORT OF MOVING AND HEALTHY LIVING BEHAVIOR IN SABILUNNAJAT BOARDING SCHOOL}

\author{
${ }^{1)}$ Fini Fajrini*, ${ }^{2)}$ Ernyasih, ${ }^{3}$ Lintang Anindita Putri, \\ ${ }^{1,2,3)}$ Program Studi Kesehatan Masyarakat, Universitas Muhammadiyah Jakarta \\ Alamat : Jl. K. H. Ahmad Dahlan, Cireundeu, Ciputat \\ *Email: $\underline{\text { f_fajrini@yahoo.com }}$
}

\begin{abstract}
ABSTRAK
Perilaku hidup bersih dan sehat adalah seperangkat perilaku yang dipraktikkan atas dasar kesadaran akan hasil belajar yang membuat seseorang atau keluarga dapat membantu diri mereka sendiri di sektor kesehatan dan berperan aktif dalam mewujudkan kesehatan masyarakat (Kemenkes RI, 2011). Tingkat kesehatan anak saat ini tidak dapat dikatakan baik, karena masih ada masalah kesehatan, terutama pada anak-anak usia sekolah. (Syah, 2019) Dalam survei pengabdian masyarakat ini dilakukan pemantauan pengendalian vektor pada santri sebagai salah satu upaya untuk menggerakan perilaku hidup bersih dan sehat di Pondok Pesantren Sabilunnajat Ciamis. Metode yang digunakan yaitu memberikan kuesioner kepada santri Pondok Pesantren Sabilunnajat pada 21-23 Februari 2020 tentang pengendalian vektor. Dari hasil pemantauan didapatkan 10,2\% santri tidur tidak menggunakan kelambu berinsektisida namun hanya $12,2 \%$ yang menggunakan kelambu berinsektisida selama 3 tahun dan hanya $11,6 \%$ yang telah menggunakan kelambu berinsektisida lebih dari 3 tahun. Kemudian hanya $24,4 \%$ yang menggunakan replen/bahan pencegahan gigitan nyamuk dan hanya 9,1\% menggunakan alat basmi nyamuk elektrik. Diharapkan pihak manajemen dapat membuat kebijakan untuk meningkatkan kesadaran siswa/santri sehingga mereka dapat hidup bersih dan sehat, sehingga dapat mencegah siswa dari berbagai penyakit berbasis vektor.
\end{abstract}

Kata kunci: pengendalian, santri, vektor

\section{ABSTRACT}

Clean and healthy living behavior is a set of behaviors that is practiced on the basis of awareness of learning outcomes that make a person or family can help themselves in the health sector and play an active role in realizing public health (Health, 2011). The current level of children's health cannot be said to be good, because there are still health problems, especially in school-age children. (Shah, 2019) In this survey of community service, vector control was monitored on students as an effort to drive clean and healthy living behavior in the Sabilunnajat Islamic Boarding School in Ciamis. The method used is giving questionnaires to Sabilunnajat Islamic Boarding School students on February 21-23, 2020 about vector control. From the monitoring results, 10.2\% of the students did not use insecticide-treated bednets, but only 12.2\% used insecticide-treated bednets for 3 years and only $11.6 \%$ had used insecticide-treated bednets for more than 3 years. Then only $24.4 \%$ used a mosquito bite prevention material and only $9.1 \%$ used an electric mosquito exterminator. It is hoped that the management can make policies to increase student / student awareness so that they can live clean and healthy, so as to prevent students from various vector-based diseases.

Keyword: control, santri, vector 
AS-SYIFA: Jurnal Pengabdian dan Pemberdayaan Kesehatan Masyarakat

\section{PENDAHULUAN}

Perilaku hidup bersih dan sehat adalah sekumpulan perilaku yang dipraktikkan atas dasar kesadaran atas hasil pembelajaran yang menjadikan seseorang atau keluarga dapat menolong dirinya sendiri di bidang kesehatan dan berperan aktif dalam mewujudkan kesehatan masyarakat (Kemenkes RI, 2011). Perilaku Hidup Bersih dan Sehat (PHBS) adalah upaya untuk memberikan pengalaman belajar atau menciptakan suatu kondisi bagi perorangan, keluarga kelompok dan masyarakat dengan membuka jalur komunikasi, memberikan informasi dan melakukan edukasi untuk mendekatkan pimpinan (advocacy), bina suasana (empowerment) sebagai suatu upaya untuk membantu masyarakat mengenali dan mengatasi masalahnya sendiri, kemudian diharapkan mereka secara sadar berupaya untuk mencegah penyakit, menigkatkan kesehatannya serta aktif menjaga kesehatan sekolah (Waluyo HB, 2018).

Penyakit yang sering muncul akibat rendahnya Perilaku Hidup Bersih dan Sehat (PHBS) diantaranya disebabkan oleh vektor dan pada akhirnya akan mengakibatkan rendahnya kualitas sumber daya manusia. Untuk itu maka diadakan gerakan masyarakat sehat dengan tujuan menurunkan beban penyakit menular dan baik kematian ataupun kecacatan, menghindari penurunan produkivitas (Kemenentrian Kesehatan, 2018). Beberapa tindakan yang dapat diterapkan untuk mengurangi resiko terjadinya penyakit yakni dengan cara: tidur menggunakan kelambu berinsektisida, serta menjaga kebersihan lingkungan sekitar.

Berdasarkan hasil pemerikasaan oleh dokter, ketika melakukan pengabdian masyarakat ditemukan beberapa penyakit berbasis vektor yang dialami santri di Pondok Pesantren Sabilunnajat. Maka dari itu perlu dilakukan pengukuran/survey sejauh mana kesadaran santri untuk hidup sehat dan bersih dalam pengendalian vektor. Tujuannya dilakukan pemantauan pengendalian vektor pada santri sebagai salah satu upaya untuk menggerakan perilaku hidup bersih dan sehat di Pondok Pesantren Sabilunnajat Ciamis.

\section{METODE}

Dalam pengabdian masyarakat yang dilakukan di Pondok Pesantren Sabilinnajat ini dilakukan juga survey untuk melihat upaya mengendalian vektor para santri. Para santri diberikan kuesioner dengan pertanyaan mengenai pengendalian vektor selama di pesantren. Indikator disurvey yaitu: tidur menggukanan kelambu tanpa insektisida, tidur menggunakan kelambu berinsektisida lebih dari 3 tahun, tidur menggunakan kelambu beinsektisida kurang dari 3 tahun, menggunakan bahan replen/bahan pencegah nyamuk, menggunakan alat basmi nyamuk elektrik. Survey dilakukan pada tanggal 21-23 Februari 2020. Pengumpulan dilakukan oleh Tim Pengmas FKM UMJ. Setelah santri menjawab pertanyaan kuesioner kemudian dilakukan analisis. Dari hasil analisis maka bisa dilihat bagaimana pengendalian vektor para santri dalam menjaga kebersihan dan kesehatan mereka.

\section{HASIL DAN PEMBAHASAN}

Dari hasil pengumpulan data, pengolahan data dan analisa data didapatkan hasil penelitian sebagai berikut:

Tabel 1. Distribusi Frekuensi Santri Tidur Menggunakan Kelambu Tanpa Insektisida di Pesantren Sabilunnajat

Sumber: Data primer, 2020

\begin{tabular}{cll}
\hline Penggunaan Kelambu tanpa Insektisida & $\mathrm{n}$ & $\%$ \\
\hline Ya & 13 & 10,2 \\
\hline Tidak & 114 & 89,8 \\
\hline Total & 127 & 100,0 \\
\hline
\end{tabular}


Berdasarkan tabel 1, dapat diketahui bahwa dari 127 santri masih ada 13 (10,2\%) santri yang tidak tidur tanpa menggunakan kelambu berinsektisida. Sedangkan sisanya 89,8\% menggunakan kelambu berinsektisida.

Tabel 2. Distribusi Frekuensi Tidur Menggunakan Kelambu Dengan Insektisida $\leq 3$ Tahun Pada Santri Di Pesantren Sabilunnajat

\begin{tabular}{cll}
\hline Penggunaan Kelambu Insektisida $\leq 3$ Tahun & $\mathrm{n}$ & $\%$ \\
\hline Ya & 14 & 12,2 \\
\hline Tidak & 101 & 87,8 \\
\hline Total & 115 & 100,0 \\
\hline
\end{tabular}

Sumber: Data primer, 2020

Berdasarkan tabel 2, dapat diketahui bahwa dari 115 santri 14 santri (12,2\%) tidur menggunakan kelambu dengan insektisida selama kurang dari 3 tahun. Sedangkan sisanya 87,8\% tidak menggunakan kelambu dengan insektisida selama kurang dari 3 tahun terakhir.

Tabel 3. Distribusi Frekuensi Tidur Menggunakan Kelambu Dengan Insektisida > 3 Tahun Pada Santri Di Pesantren Sabilunnajat

\begin{tabular}{cll}
\hline Penggunaan Kelambu Insektisida $>3$ Tahun & $\mathrm{n}$ & $\%$ \\
\hline Ya & 13 & 11,6 \\
\hline Tidak & 99 & 88,4 \\
\hline Total & 112 & 100,0 \\
\hline
\end{tabular}

Sumber: Data primer, 2020

Berdasarkan tabel 3, dapat diketahui bahwa dari 112 santri 13 (11,6\%) yang menggunakan kelambu dengan insektisida lebih dari 3 tahun. Sedangkan sisanya 88,4\% tidak menggunakan kelambu eksektisida selama lebih dari tiga tahun.

Tabel 4. Distribusi Frekuensi Menggunakan Replen/Bahan Bahan Pencegah Gigitan Nyamuk Pada Santri Di Pesantren Sabilunnajat

\begin{tabular}{cll}
\hline Penggunaan Replen & $\mathrm{n}$ & $\%$ \\
\hline Ya & 29 & 24,4 \\
\hline Tidak & 90 & 75,6 \\
\hline Total & 119 & 100,0 \\
\hline
\end{tabular}

Sumber: Data primer, 2020

Berdasarkan tabel 4, dapat diketahui bahwa dari 119 santri $29(24,4 \%)$ yang menggunakan replen/bahan pencegahan gigitan nyamuk. Sedangkan sisanya sebanyak $75,6 \%$ tidak menggunakan replen.

Tabel 5. Distribusi Frekuensi Menggunakan Alat Basmi Nyamuk Elektrik Pada Santri Di Pesantren Sabilunnajat

\begin{tabular}{cll}
\hline Pembasmi Elektrik & $\mathrm{n}$ & $\%$ \\
\hline Ya & 11 & 9,1 \\
\hline Tidak & 110 & 90,9 \\
\hline Total & 121 & 100,0 \\
\hline
\end{tabular}

Sumber: Data primer, 2020

Berdasarkan tabel 5, dapat diketahui bahwa dari 121 santri $11(9,1 \%)$ yang menggunakan alat basmi nyamuk elektrik. Sedangkan 90,9\% tidak menggunakan pembasmi elektrik. 


\section{Penggunakan kelambu insektisida dan bahan pencegahan gigitan nyamuk serta alat basmi nyamuk elektrik}

Melihat dari hasil survey bisa kita lihat sebagian besar santri telah menggunakan kelambu yang berinsektisida namun pemakainan kelambu dalam jangka panjang masih sangat kecil persentasinya, hanya sebagian kecil yang konsisten menggunaan kelambu selama 3 tahun atau lebih dari 3 tahun. Hal ini mungkin saja dikarenakan karena penyediaan kelambu berinsektisida baru diberikan beberapa tahun ini. Selain itu persentasi penggunaan bahan pencegahan gigitan nyamuk atau alat basmi nyamuk elektrik persentasenya juga kecil. Bisa jadi para santri tidak menggunakan bahan pencegahan gigitannya nyamuk atau alat basmi elektrik karena sangat repot memakainya dan dapat berbahaya bila tidak sesuai takaran. Hal ini sesuai dengan Sumantri (2015) yang menyatakan bahwa penggunaan insektisida harus tepat dan sesuai dosisnya, Karena dosis yang tinggi dapat menyebabkan pemborosan insektisida dan merusak lingkungan.

\section{KESIMPULAN DAN SARAN}

Dari hasil survey pengabdian masyarakat yang telah dilaksanakan dapat disimpulkan bahwa $10.2 \%$ santri yang tidur tidak menggunakan kelambu berinsektisida namun hanya $12.2 \%$ yang menggunakan kelambu berinsektisida selama 3 tahun dan hanya $11.6 \%$ yang telah menggunakan kelambu berinsektisida lebih dari 3 tahun. Kemudian hanya $24.4 \%$ yang menggunakan replen/bahan pencegahan gigitan nyamuk dan hanya $9.1 \%$ menggunakan alat basmi nyamuk elektrik.

Berdasarkan kesimpulan tersebut meskipun telah banyak yang menggunakan kelambu berinsektisida namun perlu lebih konsisten lagi pemakaiannya karena persentasi penggunaan kelambu selama 3 tahun atau lebih masih kecil. Maka perlu pengawasan dari pihak pengelola pesantren melihat hal ini agar penyakit akibat vektor nyamuk bisa dicegah.

\section{UCAPAN TERIMA KASIH}

Ucapan terima kasih kami sampaikan kepada seluruh pengurus Pondok Pesantren Sabilunnajat yang telah memberikan kami kesempatan melakukan survey pada pengabdian masyarakat untuk melakukan pemantauan pengendalian vektor pada para santri. Semoga hasilnya nanti bisa bermanfaat untuk sebagai bahan pengelola yayasan membuat kebijakan untuk meningkatkan kesehatan santri.

\section{DAFTAR PUSTAKA}

Waluyo HB, et al. 2018. Pedoman Pengembangan Sanitasi Sekolah Dasar. Kementerian Pendidikan dan Kebudayaan. Jakarta

Kemenkes RI. 2018. Profil Kesehatan Indonesia 2018. Kementerian Kesehatan RI. Jakarta.

Kemenkes RI. 2011. Pedoman Pembinaan Perilaku Hidup Bersih dan Sehat (PHBS). Kementerian Kesehatan RI. Jakarta

Syah, Rahdiyan,dan Iskandar Rahayu. 2019. Video Hand Hygiene Kids meningkatkan Perilaku Cuci Tangan Santri Cilik TPQ Masjid Awalulmu'minin Gamping Sleman Yogyakarta. Universitas Jenderal Achmad Yani Yogyakarta, Indonesia. Jurnal Ners dan Kebidanan. Vol 6. No 1

Sumatri, Arif. 2015. Kesehatan Lingkungan. Kencana Prenada Media Group. 